Article

\title{
Spatiotemporal Evolution of the Taiwanese-Funded Information Technology and Electronics Industry Value Chain in Mainland China
}

\author{
Yanhua Chen ${ }^{1}\left(\right.$, Suqiong Wei ${ }^{2, *} \mathbb{C}$, Hongou Zhang ${ }^{1}$ and Yuehua Gao ${ }^{2}$ \\ 1 Guangzhou Institute of Geography, Guangzhou 510070, China; csy@gdas.ac.cn (Y.C.); \\ hozhang@gdas.ac.cn (H.Z.) \\ 2 College of Geographical Sciences, Fujian Normal University, Fuzhou 350007, China; gaoyh_168@163.com \\ * Correspondence: suqiongwei@126.com; Tel.: +86-177-2403-9897
}

Received: 11 April 2019; Accepted: 1 June 2019; Published: 10 June 2019

\begin{abstract}
The Chinese Mainland has become the largest production base and a major potential market for Taiwan's information and electronics industry. Thus, studying the spatiotemporal evolution of the Taiwanese-funded information technology and electronics industry in the Mainland from the value chain perspective is necessary. This will help deepen the labor division and collaboration between the cross-strait information technology (IT) and electronics industry for sustainable development. Using Taiwanese investments during 1991-2012 and detailed firm-level data for 1976-2012, this study examines the spatiotemporal trajectory and geographical patterns of the labor division of Mainland China's Taiwanese-funded IT and electronics industrial value chain from a modular perspective. Based on the characteristics of the modular production process, the Taiwanese-funded IT and electronics firms in Mainland China are divided into four modules-parts manufacturing (PM), key parts manufacturing (KPM), complete machine manufacturing (CMM), and design and marketing (DM). We found that: (1) technology and value witnessed clear stage changes; (2) the PM and CMM modules were more decentralized, and the four modules formed five clusters; and (3) despite an increase, the degree of the four geographical divisions of labor was relatively low. This study offers implications for research and IT policy and electronics enterprises' production practices.
\end{abstract}

Keywords: industry sustainability; value chain; modularity; spatiotemporal evolution; labor division; Taiwanese-funded information technology and electronics industry in Mainland China

\section{Introduction}

With pressures from burgeoning demand for information technology, ongoing market volatility, and intensified international competition in a global economic context, both advanced and developing economies have aggressively embarked upon modular production of goods for the information technology and electronics industry (ITE industry) (The information technology and electronics industry (ITE industry) in this study consists of computer and peripheral equipment, integrated circuit and electronic components, and communications equipment.) Value chains (VCs) have been geographically fragmented and reorganized in an effort to effectively improve production efficiency and reduce costs [1-5]. In recent years, strategies for achieving and maintaining sustainability in VCs has aroused widespread interest in academic circles. A growing number of researchers have investigated sustainability in supply chain integration, including its impact on operational performance [6] or on innovation [7], as well as other causal mechanisms [8]. In this vein, the sustainability orientation is applied in this paper to analyze the spatiotemporal trajectory of Taiwan's ITE industry in Mainland China to fill the gap in the literature regarding the division of VCs from the perspective of modular 
production process, as well as the dynamics and evolutionary processes about when, where, and how industrial value is created. Another aim is to further promote the integration of product modularity and VCs in geographic research. Proposals are developed regarding the industrial cross-border integration and sustainable development.

China, undoubtedly, has exemplified outstanding performance in the ITE industry in recent decades. It is increasingly emerging as a dominant base of global manufacturing, ranking at or near the top of the global information technology and electronics players' list in electronics assembly and component manufacturing. It is also a priority investment target for leading global electronics flagships and contract manufacturers from Europe, Japan, the United States, Korea, and Taiwan (China) $[1,3,9,10]$. It is, however, of note that Taiwan played a pioneering role in integrating China into global production networks. Specifically, the production of maturing technological peripheral equipment (e.g., mouse, keyboard production) was transferred from Taiwanese computer manufacturing companies to Guangdong and Fujian provinces in Mainland China. More specifically, when the Taiwanese government relaxed its investment controls on Mainland China in 1990, Taiwanese ITE firms gradually began to move to Mainland China. This trend was further enhanced by huge market potential and opportunities in Mainland China, as well as by the challenges of rising labor costs, declining profit margins, and a shortage of engineers in Taiwan. Now, the industry has become a major Taiwanese investor in Mainland China [11-15]. Consequently, as a special case of cross-border regions with historical and ethnicities based on common language and culture, but with different economic systems and industrial structures, the two economies are closely related in the ITE sectors.

This phenomenon has attracted researchers to investigate the cross-border industrial interaction and linkages of high-tech industries between Taiwan and Mainland China. The performance and local embeddedness of some major segments of Taiwanese-funded high-tech industries ([e.g., information technology, personal computer, and integrated circuit (IC)]) in the mainland are becoming increasingly well documented [16-18]. The differences in the regional models for duplicating Taiwan's successful ITE industrial clusters in several southeast coastal regions of Mainland China [19-21] have been examined. In addition, the influences on the globalization process and/or innovation of Mainland China's high-tech industry have been compared to the influences in Taiwan [22-24]. However, we know surprisingly little about the Taiwanese investment trajectory across time and how these Taiwanese-funded firms have reorganized their value creation activities in the territories of Mainland China. Consequently, there is a lack of scientific and in-depth discussion on how to ensure the sustainable development of the Taiwanese-funded ITE industry in Mainland China.

Therefore, we focus on questions regarding the nature and characteristics of the spatiotemporal trajectory of the cross-border production network of Taiwan's ITE industry in Mainland China. Specifically, in order to contribute to the existing literature presented above, the novelty of this study comprises the following aspects: (1) It proposes a new, integrative analytical framework of modularity and VCs; and (2) it considers all the Taiwanese-funded ITE firms as a system of modular value creation, not just an individual segment or some famous companies in this area: both macro data (statistics of Taiwanese investment) and micro data (providing details on 5435 Taiwanese-funded ITE enterprises). This contributes to a better understanding of the evolution of Mainland China's Taiwanese-funded ITE industry during 1991-2012 and the distribution of value creation on behalf of these firms across different areas within Mainland China during 1976-2012. We hope that our findings will contribute to the understanding of the integration of product modularity and VCs in geographic research and enrich the theoretical landscape on intra-industry division of labor and cooperation theory.

The remainder of this paper is structured as follows. In Section 2, we present our data and research methods with respect to both temporal and spatial evolutionary processes, as well as the extent of the division of labor between Taiwanese-funded enterprises in different regions in Mainland China. This is followed by a description of the Taiwanese-funded ITE industry in Mainland China in Section 3 and a discussion in Section 4. We conclude by suggesting sustainable development strategies and discussing the limitations and potential future extensions of our research in Section 5. 


\section{Theoretical and Practical Background}

\subsection{Value Chains (VC) and Modularity}

Originally, the concept of VCs, as both a theory and a methodology, arises from the work of Michael Porter in the mid-1980s. Porter defines it as the chained linkage of related and dependent activities for delivering value from product design to final customs, involving design and production development, productive processes, marketing, and consumption recycling at the firm level. In essence, VC analysis on value-added stages refers to two dimensions: "internal" VCs-from purchasing materials to distributing, selling, and servicing the final product within a company, and "external" VCs-from raw materials to end-users as a product is manufactured and distributed, with each stage representing an industry $[25,26]$. Subsequently, VCs have expanded globally (GVC), through general business types including assembly, original equipment manufacturing (OEM), original design and manufacturing and own brand manufacturing. Accordingly, research analyzes cross-border manufacturing and distribution systems and the whole supply chains. GVC emphasizes how large and powerful leading firms and contract manufacturers bridge functional linkages and coordinate internationally dispersed activities to achieve dominance in the global market. [27,28]. Thus, GVCs have enabled developing countries to achieve industrial growth.

The theory of modularity stems from the need for separability captured by Simon's metaphor of the two watchmakers named Hora and Tempus in the 1960s [29]. He stresses that complex systems could be simplified for them to be well managed by implementing hierarchical and near-decomposable structures. Viewed through the lens of Simon's emphasis on the importance of near-decomposability, research on "modularity-as-property," "modularization-as-process," and "modularity-as-frame" has flourished in terms of the number of products and organizational architectures analyzed [30], especially as the modularity perspective has been applied from engineering [31-33] to management [34,35]. In other words, existing studies have focused on the definition of modularity [36,37], characteristics, expected benefits and risks of modularity [38,39], types and operational modes of modularity, modular organizational forms and their driving forces [40,41].

The increasing significance of a modular theory-building effort in explaining the governance of VCs and GVCs has been intensively emphasized in recent years $[5,42,43]$. The literature on this topic has scrutinized industrial/firms' VCs from the organizational modularity perspective; the work of Gereffi, Humphrey, and Sturgeon (2005) has contributed much to this effort [43]. These authors draw on the theory of modularity and their understanding of GVC to define "value chain modularity" and "modular production network" as terms for the new industrial organizational form emerging in the US electronics industry between the late 1980s and the early 1990s. VC modularity has been explained in terms of brand name firms and their contract manufacturers along with the corresponding market channels. These leading firms tend to focus on creating products and entering and defending markets; they transfer manufacturing to their turnkey suppliers operating globally. However, the division of VCs from the perspective of modular production process has not yet been given enough attention. For this reason, we divide the Chinese mainland's Taiwanese-funded ITE industry into four modules: (the parts manufacturing (PM) module, the key parts manufacturing (KPM) module, the complete machine manufacturing (CMM) module, and the design and marketing (DM) module), while also taking the characteristics of its modular manufacturing processes and main businesses into account. Thus, we contribute to the body of literature which already exists on this topic.

\subsection{VCs and Industrial Clustering}

It is the general consensus that the level of power exertion and value capture are not evenly spread among participants in different stages of the chain. The distribution of power and value capture also varies by geographic region. The interaction between "slicing up the value chain internationally" "Slicing up the value chain" [44] can be considered to refer to vertical specialization [45,46], outsourcing [47,48], disintegration of production [49], fragmentation of 
production [50], and intra-product specialization [51], among other things.) and industry clustering was first examined by Krugman [44], who discussed the means of reorganizing various nodes of production in a firm's VC in different locations.

Further studies on how companies are embedded in GVCs, as well as on industrial clustering and upgrading, have been conducted to build on this theoretical perspective. For example, Humphrey and Schmitz $[52,53]$ examined the linkage between industrial agglomerations and GVCs governance. These authors identified how global industrial participants, especially developing country producers, insert into GVCs by proposing the following four paths: arm's length market relations, network, quasi-hierarchy, and hierarchy. In addition, the authors analyzed how the four paths of insertion in GVCs affect the upgrading of industrial clusters with regard to different types of upgrading (e.g., process upgrading, product upgrading, functional upgrading, interpectoral upgrading).

From a practical point of view, the pattern of geographic distribution and regional division of labor on a few industrial VCs has been analyzed, including apparel and footwear [27,54], automobile [53,55], bicycles and electronics [56,57], and wood furniture [58]. However, these empirical research papers conduct static analysis; there is a lack of literature on the spatiotemporal patterns of industrial VCs. More specifically, there is a gap in the literature regarding the dynamics and evolutionary processes about when, where, and how industrial value is created. In fact, Sturgeon et al. (2008) stressed that it is important not to ignore the need to understand the spatial processes and the various roles that local agglomerations play within spatially extensive VCs. Furthermore, he identified the need to map activities that tend to be concentrated in particular places, even as the geographic "footprint" of linked economic activity expands. Therefore, we assess the spatiotemporal evolution of industrial VCs along modular production processes. The specific focus of our investigation is Taiwanese-funded ITE industry VCs in Mainland China. On this basis, new research conclusions in this field are generated.

\subsection{Practical Background}

The ITE industry has a highly fragmented VC among the world's geographically extensive and dynamic manufacturing processes. However, it also exhibits an extremely modular case, which enables dealing with the complexity at technology and product level for the purpose of research [42,59]. IBM provided the first and most significant foray into modular production (the System/360) in 1964. This accelerated the adoption of modular organization on behalf of other electronics companies, which jointly engaged in the modular design, manufacturing, and integration processes of electronic products [36]. This enabled companies to focus on core competitive modules such as DM, while outsourcing production, manufacturing, and other non-core modules to external companies. As a consequence, in the age of modular networks led by IBM, global ITE companies gradually simplified their product design and assembly operations within the modular architecture. "Modular clusters" were formed composed of system designers, module integrators, and module manufacturers, which were further divided into special module manufacturers and general module manufacturers (Figure 1). This development is in line with the Shih's "smiling curve" [60], evidenced by the performance of leading global firms (Figure 2). Specifically, in the global ITE industry, system designers and brands, and marketing firms (module integrators) grasp the highest share of value in the market. General module firms account for the smallest share and special module firms and OEM firms (module integrators) account for the remainder of the value created.

The production of electronics modules for European and American companies was transferred to Taiwan at an early stage. Thus, the country has exemplified outstanding performance in computer OEM, electronic components manufacturing, and IC design and OEM. It dominates the market for general modules and OEM at the low end of the smiling curve and is involved in the marketing and management of mid- to high-end special modules and brands (e.g., TSMC, Delta Electronics, Foxconn, Quanta, Compal, Pega Design, Wistron, and Acer). Thus, Taiwan occupies an important place in the global ITE industry. For example, Taiwan was second only to the United States with a total number of 125 companies in the Global IT Top 100 during 1998-2009 (Date source: Global IT Top 100 
of -Business Week- in America). Also, the ITE industry has become one of the fastest-growing and largest industries in the Chinese mainland, with the average annual growth rate, industrial economy contribution rate, and export contribution rate accounting for $22.0 \%, 51.0 \%$, and $32.7 \%$ (Date source: -Chinese Statistics Yearbook in 2001-2013-). In this respect, it cannot be ignored that Taiwan has acted as a big engine to the booming development of the Chinese ITE industry due to a large number of Taiwanese investments, which is triggered by the worsening investment environment within Taiwan and the promotion of cross-strait economic and trade relations since the late 1980s. For example, the proportion of Taiwanese-funded ITE firms in foreign investment in China was more than $50 \%$ in 2005 (Date source: -Chinese Statistics Yearbook on Information and Electronic Industry (2005)-). In 2013, 96.1\% of output value (hardware) of the Taiwanese ITE industry was produced in Mainland China (Date source: Taiwan's Institute for the Information Industry). To a large extent, the layout of geographical functional modules of the Taiwanese ITE industry on the Chinese mainland defines the industry for the Mainland. For this reason, this paper deconstructs VCs in the ITE industry from the perspective of product modularity to discuss the characteristics, spatial patterns, and dynamic process of Taiwanese-funded ITE industry in Mainland China.

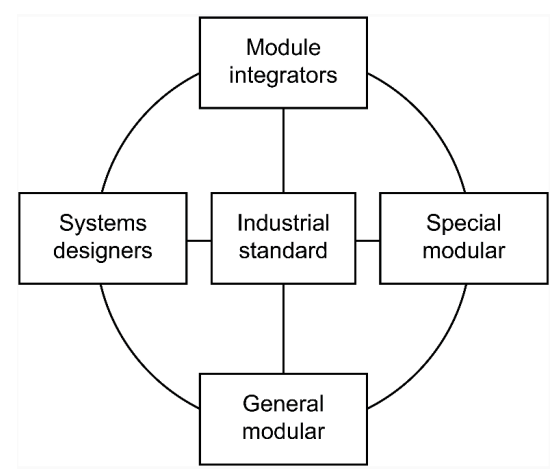

Figure 1. The modular manufacturing network of information and electronic enterprises.

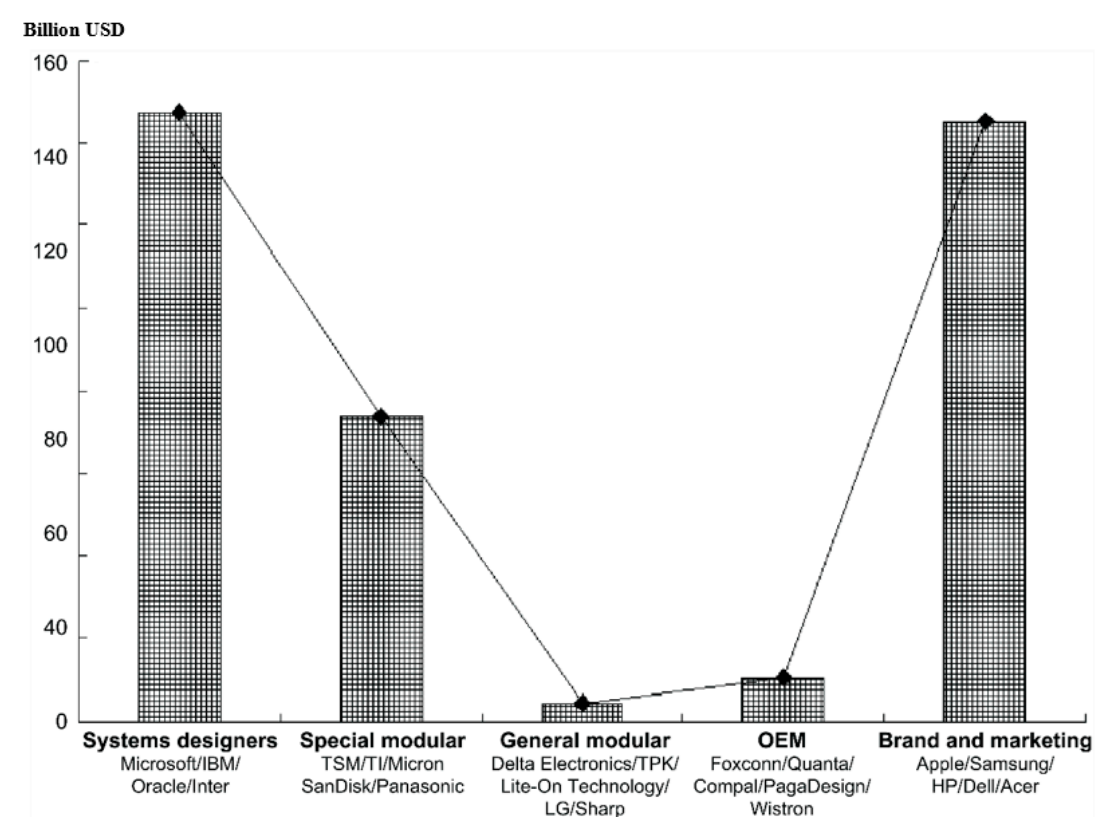

Figure 2. The value curve of global information and electronic industrial modules. Note: The data are obtained from the world's top 500 IT companies published by Fortune magazine in 2012 and a survey of the statistics of 2000 enterprises statistics conducted in 2012 by the Common Wealth magazine. Five modular groups are categorized according to the main businesses and their relative importance, and thus, their high-end technology monopoly. The top five companies in each category were selected based on net profits. 


\section{Data and Methods}

\subsection{Division of Taiwanese-Funded ITE Modular Firms in Mainland China}

With regard to the characteristics of modular manufacturing networks and VCs (Figures 1 and 2), the Taiwanese ITE companies in Mainland China can be categorized into four modules (with respect to their main area of business): (1) PM, (2) KPM, (3) CMM, and (4) DM (Figure 3). Firm data were collected from the 2012 Directory of Taiwanese Businesses in Mainland China and the official websites of companies, including 5435 ITE companies, during 1976-2012.

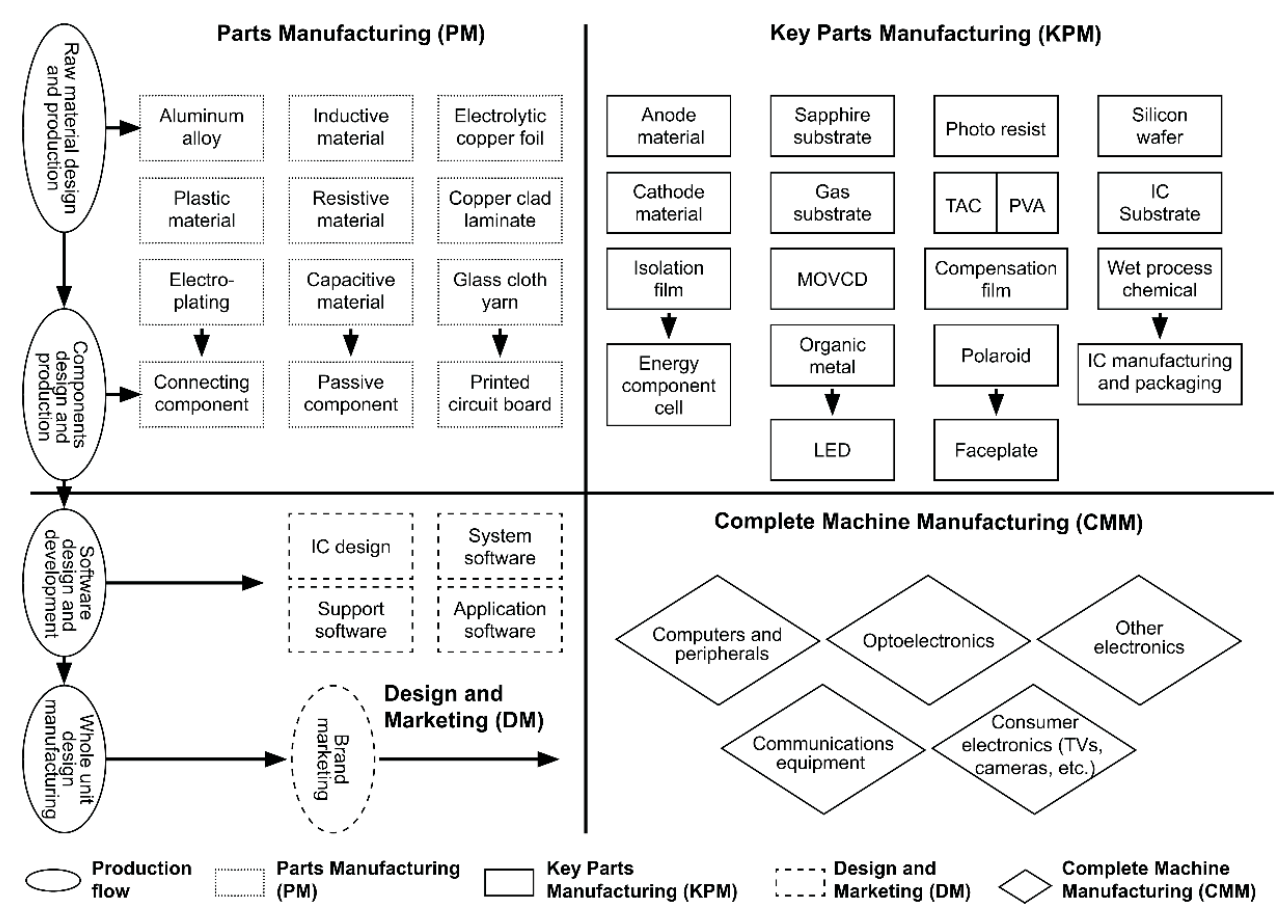

Figure 3. Production process and the value chain of the information and electronics industry. Source: Authors' construction.

\subsection{Temporal Evolution}

The development of Taiwanese-funded ITE module companies in the mainland was examined in stages through statistical description based on types and investments of those companies in the 1991-2012 Statistical Table for Approved Investments in Mainland China by Regions from the Investment Commission of Taiwanese Ministry of Economic Affairs, as well as quantitative proportions of newly built Taiwanese ITE companies between 1991 and 2012. It should be noted that, because the upsurge of Taiwanese investment in Mainland China started in 1991 and the latest statistical date of the directory of Taiwanese enterprises in Mainland China is 2012, this analysis considers the time period between 1991 and 2012.

\subsection{Spatial Evolution}

Administrative divisions for the study years were uniformly processed by spatial analysis based on the 2010 administrative divisions for Mainland China, taking prefecture-level cities (including municipalities and sub-provincial cities) as a research unit. After excluding Tibet, Gansu, and Qinghai (where there are no Taiwanese-funded electronics module companies), prefecture-level cities totaled 285. ArcGIS was used to visualize the process of the temporal and spatial evolution of the Taiwanese-funded ITE industry value chain in Mainland China. First, the vector data of provinces and municipalities were converted into shp layers in ArcGIS 10.1. Second, the four categories of newly built Taiwanese-funded module companies in Mainland China's prefecture-level cities in each stage were integrated into 
China's map for a more intuitive longitudinal and lateral comparison. On this basis, their spatial pattern and evolution trends were analyzed at both the macro- and meso-spatial scales.

In addition, in order to measure the degree of geographical specialization of Taiwanese-funded electronics module companies (i.e., to understand the correlation of the spatial layout between various module companies) in Mainland China and generate insight for sustainability policy, we apply the niche overlap method [61], which is widely used in the fields of biology, economics, and other disciplines to evaluate the degree of the common use and competition for certain resources. Scholars have developed many kinds of niche-overlapping calculation formulas, among which the Pianka formula is the most widely used [61]. On the basis of previous research results, the formula for the niche overlap in this paper is as follows:

$$
O_{i j}=\left(\sum_{j=1}^{n} p_{i j} p_{k j}\right) /\left[\left(\sum_{j=1}^{n} p_{i j}{ }^{2}\right)\left(\sum_{j=1}^{n} p_{k j}^{2}\right)\right]^{1 / 2}
$$

where $O_{i j}$ represents the niche overlap between $i$-th and $j$-th modules; $p_{i j}$ and $p_{k j}$ represent the proportions of $i$-th and $j$-th modules in territory $j$ with respect to the total numbers of modules. This ratio indicates the proportion of spatial territory $j$ to the total spatial scale. Prefecture-level city units were abstracted as equivalent spaces with a constant value of $1 / 285$.

\section{Taiwanese-Funded ITE Industry in Mainland China}

In the late 1980s, the exchange rate of the new Taiwanese dollar to the U.S. dollar appreciated sharply. Taiwan faced rising wages, labor shortage, and the added value created was low. Expanding and deepening industrial VCs was urgently necessary, as was the promotion of high-tech industries, which forced an outward shift of the ITE industry characterized by labor-intensive and export-processing activities. Mainland China, which was in the reform and opening-up period at that time, became the best choice for Taiwanese electronics manufacturers' direct investment due to geographical proximity and cultural similarities, as well as the availability of much lower labor costs $(\$ 36.0 /$ month in the early 1990 s, which was only $4.8 \%$ of Taiwanese labor costs). In 1991-2012, the average annual growth rate of Taiwan's total investment in Mainland China's ITE industry rose to $116.44 \%$ (Figure 4). Taiwan's investment in China accounted for $34.97 \%$ of Taiwan's total foreign investment, ranking the first among industries. Individual investments also rose rapidly, being 50 times higher in 2012 (\$31.48 million) compared with that of 1991 (Figure 4). Investments in the ITE industry primarily comprised electronic components manufacturing, computers, electronic, and optical products, with these products accounting for $96.85 \%$ of total investment (Figure 4). Taiwanese-funded companies primarily consisted of PM and CMM modules, with an average proportion accounting for $70.40 \%$ (Figure 5).

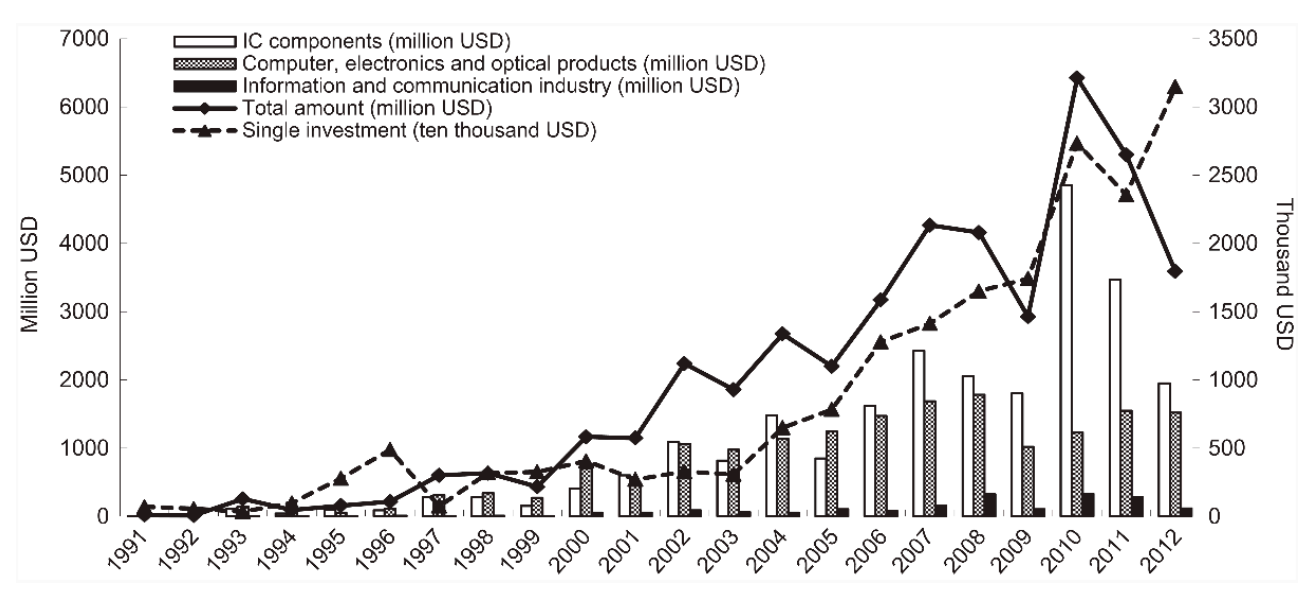

Figure 4. Investments of Taiwan-invested information and electronics industry in the mainland during 1991-2012. Source: Statistical Table for Approved Investments in Mainland China by Regions from the Investment Commission of Taiwanese Ministry of Economic Affairs. 


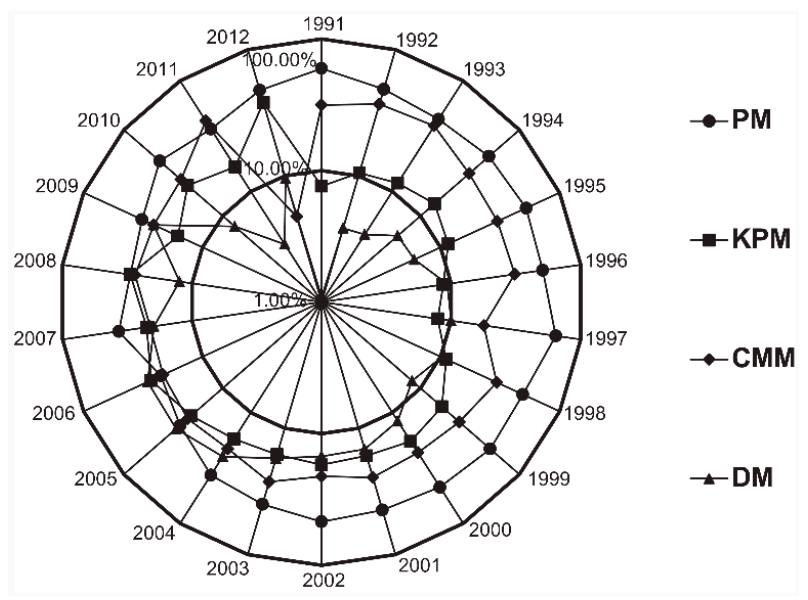

Figure 5. Proportion of newly increased four module firms funded by Taiwan in Mainland China during 1991-2012. Source: 2012 Directory of Taiwanese Businesses in Mainland China and companies' official websites.

According to the inflexion point of the amount and individual size of Taiwanese investment in Mainland China's ITE industry (Figures 4 and 5), the history of Taiwanese investment in the mainland during 1991-2012 could be divided into three stages:

(1) The first stage (before 1997) could be named "the general module supplier stage," during which different kinds of products were supplied, but only to Taiwanese companies. During this stage, ITE companies were small in number and scale, with an average individual investment of only $\$ 1.57$ million. These companies had a low level of technical advancement, with the proportion of PM module companies (e.g., manufacturers of resistors, capacitors, connectors, and other electronic components) at $52.84 \%$. Although CMM module companies accounted for $31.11 \%$, most of them were engaged in the assembly of low-tech devices such as radios, telephones, electrical instrumentation, computer keyboards, mouse, audios, and microphones. Similarly, there was a small proportion $(10.30 \%)$ of KPM module companies such as IC and battery companies that dealt only with packaging, without being involved in core design and manufacturing. Software module companies accounted for merely $5.75 \%$, most of which were small software developers with 10-50 employees. Furthermore, Taiwanese investors, in this stage, were small- and medium-sized export-processing businesses with less than 500 employees, and they took advantage of the low-cost environment in Mainland China. Raw materials and machinery equipment were from Taiwan, and R\&D and marketing networks were concentrated in Europe and America. Thus, a cross-regional vertical modular division of labor mode of "taking orders in Taiwan, producing in Mainland China, exporting to Hong Kong" prevailed.

(2) The second stage (1998-2005) could be called "the special module supplier and integrated module suppliers cluster stage," during which the regional integration module supply network between Taiwan and Mainland China was formed. After the outbreak of the Asian financial crisis in 1997, Mainland China's excellent investment environment ushered in Taiwanese ITE companies' investment boom. Investment expanded from simple computers and peripherals to other industries such as communications, optoelectronics, IC, and software design, with the proportions of newly built KPM and DM module companies increasing to $16.72 \%$ and $16.45 \%$, respectively. Thus, the industry began to exhibit large-scale industrial diversification, and high-tech features. For example, nearly 90\% of 2005 Top 100 Taiwanese listed electronics companies made large-scale investments in Mainland China, including: Quanta, Compal, Wistron, Tatung, and Inventec, the world's top five notebook manufacturers (CMM module companies); Foxconn, Delta, and Nanya PCB, the world's largest computer peripheral and electronic component manufacturers (PM module companies); and ASE, TSMC, MediaTek, 
and AU Optronics, the world's famous semiconductor and optoelectronics manufacturers (KPM module companies). The investment of large companies accelerated the investment of related upstream and downstream small- and medium-sized enterprises (SMEs) to establish factories around them, gradually forming mature manufacturing systems and complete supply chains, in which large, medium, and small Taiwanese ITE companies cooperated as well. However, Mainland China still played the role of Taiwanese export processing base, and the cross-regional modular division of labor mode of "Taiwan order reception, mainland production" continued.

(3) The third stage (2006-2012) could be named "the integrated module supplier cluster stage." Despite a reduced number of companies, this stage was characterized by individual investments of a higher magnitude and technical level and upgraded VC. Specifically, individual investments expanded 13 times compared with the first stage to $\$ 20.46$ million; investments in the information and communications sector increased by 2.3 times compared to the second stage, and the proportions of KPM and DM modules continued to rise, with nearly $40 \%$ of the top 100 Taiwanese electronics companies' established R\&D and marketing centers in Mainland China. In particular, with the outbreak of the global financial crisis in 2008, the global personal computer market shrank, and Taiwan's European and American export-oriented development model was constrained. Therefore, Mainland China became Taiwan's indispensable new market due to its huge market potential and rapid economic development. The Taiwanese ITE industry in Mainland China transformed from processing-led to market expansion plus processing, thus forming a modular company value network served by a complete industrial supporting system. Hence, a diversified division of labor mode with coexisting "vertical labor division" and "horizontal labor division" emerged in the cross-strait ITE industry.

\section{Discussion}

\subsection{Macro Scale: Point-to-Axis Distribution from Eastern Coastal Areas to Inland}

Before 1997, the four categories of module companies were concentrated mainly in the prefecture-level-or-higher cities in the eastern coast of the mainland, while in the midwestern regions, only sporadic distribution was found in provincial capitals (Figure 6). Interregional disparity was great and there were clustered centers. Furthermore, four categories of module companies had a high degree of overlap in the clustered centers. For example, PM module companies were highly concentrated in the southern coastal cities such as Shenzhen, Dongguan, and Xiamen, and the number of the other three module companies (KPM, CMM, and DM) was also large in these three central cities. DM companies-the smallest in number-were highly concentrated in two megacities-Shanghai and Beijing_-and sparsely distributed in other regions.

By 2005, the geographical division of labor began to appear in the Taiwanese-funded ITE industry modules in Mainland China. All four modules were in a diffused state in terms of spatial geography, of which KPM and DM modules exhibited the maximum diffusion intensity (Figure 6). This was clear, on the one hand, as diffusion expanded from south to north, with an increased proportion of firms in the Yangtze River Delta area, suggesting a point-to-axis investment pattern. On the other hand, diffusion expanded from urban centers to outlying cities, with intensified concentration of high-value module companies in the central cities and low-value module manufacturers in the outlying cities such as Suzhou in the Yangtze River Delta, Dongguan and Huizhou in the Pearl River Delta, and Qingdao in the Bohai Rim Region. Regarding regional distribution, it was manifested as the formation of central-peripheral relations between low-value modules concentrated outside of cities and high-value modules concentrated in cities, such as Shanghai, Nanjing-Suzhou, Ningbo, Shenzhen-Dongguan, and Huizhou.

The development trends during 2006-2012 continued and the east-to-west diffusion was intensified, the Chengdu-Chongqing-Xi'an triangular agglomeration center was newly added, and the agglomeration force of Xiamen and Fuzhou was enhanced. Westward diffusion of PM and CMM module 
firms was the most obvious and covered a broad geographical scope. Software design and marketing firms agglomerated most prominently in megacities and provincial capitals. The geographical relationship between low-value and high-value modules was still manifested in two ways. One was the geographical overlapping, that is, local value module combinations, such as R\&D and marketing centers clustered with IC and software industries in Shanghai. The other was proximal combinations, with Shanghai and Suzhou; Suzhou and Anhui Wuhu; and Shenzhen and Dongguan, Huizhou, and Jiangmen being the most prominent ones.

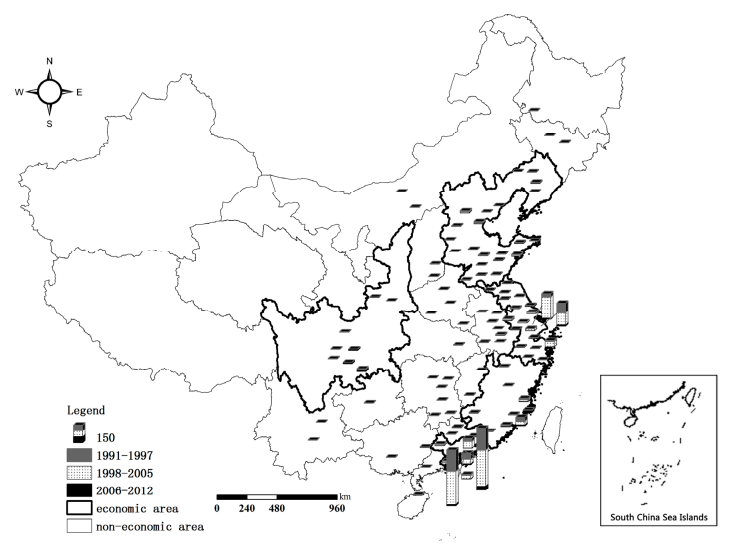

(A)

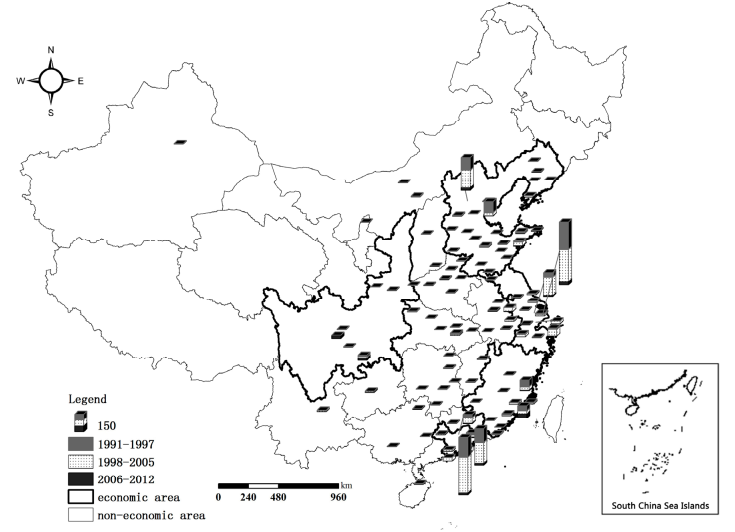

(C)

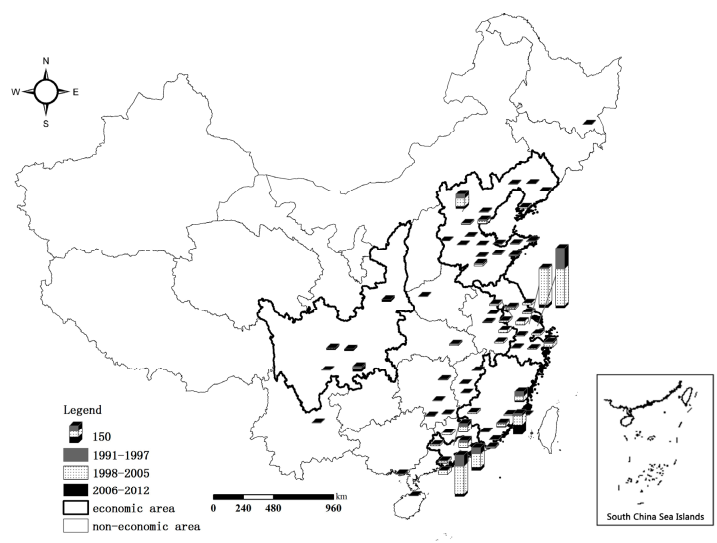

(B)

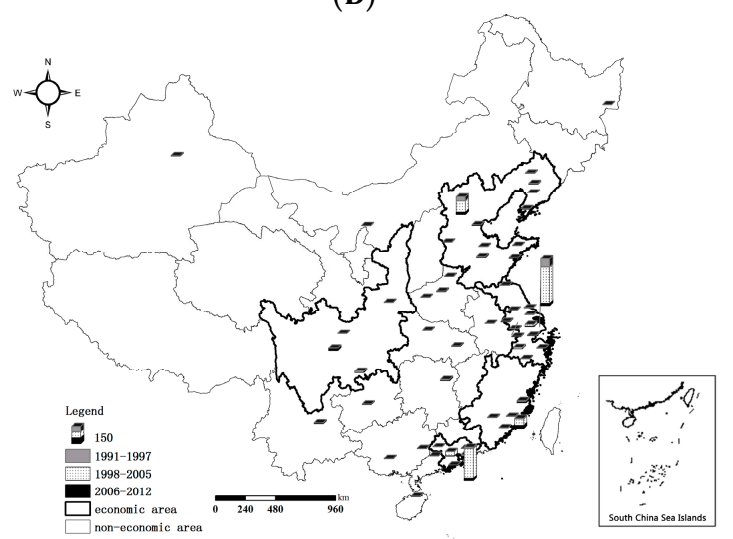

(D)

Figure 6. Spatial distribution of the expansion of the four modules of information and electronics firms funded by Taiwan in the mainland during 1991-2012. Note: (a) PM, (b) KPM, (c) CMM, and (d) DM. Source: 2012 Directory of Taiwanese Businesses in Mainland China and companies' official websites.

Finally, it should be noted that the diffusion trajectory of Taiwanese ITE module companies in Mainland China shared similarities with foreign direct investment (FDI) companies in China. They both exhibited central-to-peripheral city, eastern coastal area-to-inland diffusion trends, with a point-to-axis investment pattern. Meanwhile, mid-to-downstream businesses in the VC (e.g., PM and CMM modules) were spatially scattered. In contrast, mid-to-upstream businesses in the VC (e.g., KPM and DM modules) were spatially concentrated and prone to be distributed in developed cities, such as Shanghai, Shenzhen, and Beijing. The difference, however, between Taiwanese-funded electronics value module companies and other FDI companies was that the Taiwanese initially preferred Shenzhen, Dongguan, Fuzhou, and Xiamen in the southern coastal region, then turned northward to Shanghai, Jiangsu in the Yangtze River Delta and Beijing, Tianjin, and other places in the Bohai Rim Region. On the other hand, the FDI distribution patterns of other companies in Mainland China has changed little between 1991 and 2010 and were mainly concentrated in the Pearl River Delta and the Yangtze River Delta [62]. 


\subsection{Meso Scale: Geographical Division of Labor in Five Highly Clustered Areas}

From Figure 4 and Table 1, it may be seen that since the late 20th century, the Taiwanese-funded ITE industry in Mainland China first diffused and then clustered, eventually forming five highly clustered areas: (1) the Pearl River Delta, (2) the Yangtze River Delta, (3) the Western Taiwan Straits Economic Zone, (4) the Bohai Rim Region, and (5) the West Triangle Economic Zone. The location selection of Taiwanese investments in Mainland China has this clustering feature due to the influence of bilateral politics and regional culture. As a result, earlier on, most Taiwanese businesses invested in the West Coast Economic Zone since both zones face each other across the Taiwan channel and are thus neighbors. However, investments have now gradually expanded to the Yangtze River Delta and Pearl River Delta along the southeast coast. Over time, with the establishment of cross-strait political links and the implementation of China's "Western Development" strategy in the late 20th century, Taiwanese investments have expanded to the central and western regions of Mainland China as well. Finally, the agglomeration phenomenon left a significant mark on the clustering process. This conforms to the "geographical distance attenuation principle" and the "spatial interaction law." Each cluster assumed different roles as follows:

1. The Bohai Rim Region's cluster was mainly responsible for high-tech, high value-added KPM $(9.8 \%)$ and CMM (17.0\%), such as optoelectronic devices and semiconductors. In addition, the area also assumed partial DM functions (17.7\%), especially Beijing, which has become one of Taiwanese electronics companies' major marketing centers in Mainland China. However, Taiwanese companies are relatively loosely connected and isolated within this area and they are far smaller than those in the Yangtze River Delta and Pearl River Delta.

2. The Yangtze River Delta cluster comprising Shanghai, Suzhou, Ningbo, Nanjing, Hangzhou, Wuxi, and so on was the area with the most complete value network and strongest comprehensive contributor to the development of Taiwanese modular ITE companies in Mainland China. The proportion of newly developed module companies other than PM module companies was highest in Mainland China, with 17 of the top 10 listed semi-conductor companies and top 10 listed optoelectronic companies in Taiwan settled there. Shanghai, Yangtze River Delta's center, assumed the functions as regional headquarters and R\&D center of Taiwanese-funded companies. Clearly, R\&D, manufacturing, and sales were developing strongly and simultaneously in the Yangtze River Delta.

3. The Pearl River Delta cluster comprising Dongguan, Shenzhen, Huizhou, Guangzhou, Zhongshan, Zhuhai, and others was the oldest and largest area with high proportions of four module companies, where a complete range of electronics supporting systems has been established. However, low-value module companies had concentrated and were thriving, especially PM modules such as production and assembly of electronic components, computers and peripherals, and audiovisual products. Clearly, the area mainly assumed a manufacturing function, but had weak development prospects due to intensifying market competition. Thus, processing SMEs gradually closed down, moved northward, or were forced to transition toproducing other modules in recent years.

4. The Western Taiwan Straits Economic Zone cluster, covering places such as Xiamen, Fuzhou, Zhangzhou, and Ganzhou, was the first area to receive Taiwanese-funded companies. However, the area had a relatively simple form of business that focused on the development of KPM modules, primarily the production and manufacturing of optoelectronics and their components, with the proportion of new additions reaching up to $29.4 \%$ during 2006-2012. It is noteworthy that Western Taiwan Strait's software design companies were growing well (25.0\%). These companies were mainly concentrated in Xiamen and Fuzhou. This is closely related to software parks established in Fuzhou and Xiamen 20 years previously. At present, software parks in the two cities have become influential software industry clusters in the Fujian province and even in Mainland China. However, because the technology trading market and product market in this 
area are too small to be integrated in the ITE industrial chain such as the Yangtze River Delta and the Pearl River Delta, it can be expected to continue to focus on Taiwanese-funded photoelectric and software industry.

5. The West Triangle's cluster, comprised of places such as Chengdu, Chongqing, Xi'an, Mianyang, Neijiang, had the shortest development history. The area began to develop rapidly after 2005 and has become the third-largest investment destination, surpassing the Bohai Rim Region and the Western Taiwan Straits Economic Zone. However, the area also focused on the simplest form of business: the manufacturing and assembly of computer components and CMM modules. Some Taiwanese listed computer giants have also all gathered here, one after another, such as Foxconn, Quanta, Compal, Wistron, and Inventec.

Table 1. Proportion of newly increased four modules at different stages in five areas of Mainland China.

\begin{tabular}{|c|c|c|c|c|c|c|c|c|c|c|c|c|}
\hline & \multicolumn{3}{|c|}{ PM } & \multicolumn{3}{|c|}{ KMM } & \multicolumn{3}{|c|}{ CMM } & \multicolumn{3}{|c|}{ DM } \\
\hline & $\begin{array}{l}\text { Before } \\
1997\end{array}$ & 1998-2005 & 2006-2012 & $\begin{array}{l}\text { Before } \\
1997\end{array}$ & 1998-2005 & 2006-2012 & $\begin{array}{l}\text { Before } \\
1997\end{array}$ & 1998-2005 & 2006-2012 & $\begin{array}{l}\text { Before } \\
1997\end{array}$ & 1998-2005 & 2006-2012 \\
\hline Bohai Rim Region & $6.60 \%$ & $3.60 \%$ & $3.50 \%$ & $15.20 \%$ & $9.40 \%$ & $9.80 \%$ & $22.40 \%$ & $14.40 \%$ & $17.00 \%$ & $29.60 \%$ & $13.70 \%$ & $17.70 \%$ \\
\hline $\begin{array}{c}\text { Western Taiwan } \\
\text { Straits Economic Zone }\end{array}$ & $7.60 \%$ & $4.70 \%$ & $12.10 \%$ & $12.20 \%$ & $9.80 \%$ & $29.40 \%$ & $12.00 \%$ & $5.00 \%$ & $20.20 \%$ & $5.70 \%$ & $7.30 \%$ & $25.00 \%$ \\
\hline Pearl River Delta & $60.70 \%$ & $57.20 \%$ & $22.40 \%$ & $32.50 \%$ & $30.20 \%$ & $19.60 \%$ & $30.20 \%$ & $37.10 \%$ & $20.20 \%$ & $12.50 \%$ & $33.30 \%$ & $16.20 \%$ \\
\hline $\begin{array}{l}\text { West Triangle } \\
\text { Economic Zone }\end{array}$ & $1.00 \%$ & $0.60 \%$ & $32.80 \%$ & $2.50 \%$ & $1.00 \%$ & $20.60 \%$ & $1.60 \%$ & $1.60 \%$ & $20.20 \%$ & $1.10 \%$ & $2.10 \%$ & $17.70 \%$ \\
\hline
\end{tabular}

Source: 2012 Directory of Taiwanese Businesses in Mainland China and companies' official websites.

\subsection{Quantitative Measures for the Degrees of Geographical Division of Labor}

The degree of niche overlap between value module companies was compared (Table 2). As can be seen, the niche overlap between various value module companies was generally high, except for the PM and DM modules. The KPM and CMM modules had the highest spatial overlap, followed by the CMM and DM modules, while the PM and DM modules were the lowest. The niche overlap between PM, CMM, and KPM modules is higher because the ITE industry has a long industrial chain, allowing it to focus on the forward-backward industrial correlation and cost benefits brought by business agglomeration. Modules located in the high end of the VC (e.g., KPM and DM modules) have similar location preferences (e.g., strong science and technology talents/levels and rapid distribution of information), so their spatial distributions were highly similar. Modules in the low end of the VC (e.g., PM module) preferred low-cost locations, for which preferences differed depending on the modules in the upstream of the VC. The two were quite different in spatial layout. By 2012, the niche overlap between the PM module and other modules first rose and then dropped, showing a downward trend, the same as the KPM and CMM modules. The niche overlap between the KPM and DM modules first dropped and then rose, while the niche overlap between the CMM and DM modules increased annually, showing a catch-up trend. Therefore, the geographical division of labor between the CMM modules and KPM or DM modules continued to weaken, showing a tendency to concentrate in the same area. The geographical division of labor between the DM module and KM, CMM, DM modules and between the KM module and CMM and DM modules, conversely exhibited a developing trend.

Table 2. Niche overlapping degrees among the development of the four modules in Mainland China.

\begin{tabular}{ccccccccccccc}
\hline & \multicolumn{9}{c}{ Before 1997 } & \multicolumn{1}{c}{ 1998-2005 } & \multicolumn{3}{c}{ 2006-2012 } \\
\cline { 2 - 13 } & PM & KPM & CMM & DM & PM & KPM & CMM & DM & PM & KPM & CMM & DM \\
\hline PM & 1 & 0.7294 & 0.7811 & 0.4064 & 1 & 0.8016 & 0.8538 & 0.5716 & 1 & 0.6173 & 0.6459 & 0.4365 \\
KPM & - & 1 & 0.9481 & 0.8612 & - & 1 & 0.9212 & 0.8052 & - & 1 & 0.9123 & 0.8156 \\
CMM & - & - & 1 & 0.8178 & - & - & 1 & 0.8737 & - & - & 1 & 0.9088 \\
DM & - & - & - & 1 & - & - & - & 1 & - & - & - & 1 \\
\hline
\end{tabular}

Source: 2012 Directory of Taiwanese Businesses in Mainland China and companies' official websites. 
In summary, despite the low degree of geographical division of labor between Taiwanese-funded ITE modules in Mainland China between 1991 and 2012, there have been some developments, which were mainly manifested in the spatial agglomeration between the CMM and DM modules. In particular, the significant diffusion of the KPM and PM modules has promoted the modular division of labor between various regions in mainland China.

\section{Conclusions}

\subsection{Concluding Remarks and Suggestions}

Modularization, fragmentation, and decentralization are the evolution trends of product value creation. Only by giving full play to the division of labor along the VC whereby regional advantages are exploited can the effective functioning of the entire VC be facilitated, and industrial restructuring and upgrading be promoted. From this perspective, the spatiotemporal evolution of the Taiwanese modular VC in Mainland China and the progression of geographical specialization degrees is empirically studied. The study progresses by analyzing the ITE industry as an example using three methods: statistical description, spatial visualization analysis with ArcGIS, and niche overlap. To some extent, this study is conducive to the integration of product modularity and VCs in geographic research and enriches the theoretical landscape on intra-industry division of labor and cooperation theory.

The results show the following:

1. Temporal evolution: Before 1997, a small number of small-scale, low-tech PM module suppliers were in the majority. These suppliers only provided different kinds of products to companies in Taiwan and exemplified a cross-strait vertical modular division of labor mode. From 1998 to 2005, several large-scale, industrially diversified, high-tech special module suppliers and integrated module supplier clusters were in the majority, which formed the regional integration module supply network connecting the Taiwanese ITE industry with Mainland China. From 2006 to 2012 , integrated modular supplier clusters were in the majority, which were small in number but large in scale, had high capital input, and high technical level. They transformed from processing-orientation to market expansion plus processing. Thus, a diversified modular division of labor mode with coexisting "vertical labor division" and "horizontal labor division" emerged in Taiwan and Mainland China.

2. Spatial evolution: Since the start of Taiwanese investments in the mainland's ITE industry, the value module division of labor between prefecture-level city units has exemplified diffusion trends from south to north and east to west. Different modules are combined in two ways: local combination and proximal promotion. The spatial distribution of low-value modules is more decentralized, whereby companies diffused mainly toward adjacent domains (e.g., the Yangtze River Delta and Pearl River Delta areas). Eventually, Taiwanese-funded ITE industry clusters with respective roles were formed: the modular company value network of the Yangtze River Delta area with simultaneous development of R\&D, manufacturing and marketing of IC, computers, monitors, and software; the Pearl River Delta area with a complete range of electronic products but with large numbers of low-value module companies; the Western Taiwan Straits Economic Zone clustered with KM module companies such as optoelectronics and component manufacturers; the West Delta area involved in the production and assembly of computer components and CMM; and the Bohai Rim Region with R\&D and marketing of high-tech, high value-added KM, CMM, and DM modules, though this area was less apparently agglomerated.

3. According to the quantitative measurement results of the niche overlap method, the degree of the geographical division of labor between Taiwanese-funded ITE module firms in Mainland China was still low, but it has made some developments that are seen mainly in the spatial agglomeration of CMM and DM modules. In particular, the substantial diffusion of KPM and PM modules promoted the modular division of labor between Mainland China's regions. 
Consequently, to promote the geographical and rational division of labor of Taiwanese-funded ITE value modules in Mainland China, we argue that the VC needs to be extended as follows:

1. Geographical extension: While accelerating the pace of development of eastern coastal areas, particularly the Yangtze River Delta and Pearl River Delta labor-intensive PM module firms, towards midwestern regions that have cost advantages, these regions should constantly improve their industrial infrastructure facilities and institutional environment to take over the low-end value modules in the eastern areas and become Taiwan's new ITE manufacturing base.

2. Hierarchical extension: Eastern coastal areas, especially Beijing, Shanghai, and Shenzhen, should develop high-value module agglomeration. For example, the Yangtze River Delta should further extend the industrial VC by taking advantage of its active capital market, good innovation atmosphere, and vast consumer market. Further, it should strengthen its competence of the Taiwanese ITE industry's R\&D and marketing centers in Mainland China, by seeking cooperation with local governments and businesses for building technical standards, jointly designing products suitable for Mainland China's market, establishing specialized distribution channels and marketing outlets, among other things.

\subsection{Limitations and Future Research}

In brief, our results shed some new light on research over the spatiotemporal evolution of the cross-border business, especially on understanding the trajectory and interaction of the ITE industry between Mainland China and Taiwan. This will guide further research and practice for promoting industrial restructuring and upgrading in cross-strait regions. However, some potential limitations of this study should be explicitly recognized. On the one hand, the reason different value modules of the Taiwanese-funded ITE industry organized in the different areas in the mainland have not been investigated is owing to space limitations. This will be a topic for future research, whereby a suitable indicator system will be developed and different individual companies will be interviewed. In this way, the strategies for moving up the VC, enhancing Mainland China's competence, and further upgrading their position within the global economy, can be defined. On the other hand, we have not discussed the inter- or intra-relationship between Taiwanese-funded multinational enterprises (MNEs) and local firms in Mainland China.

The spatiotemporal evolution of the organic linkage between original and rebuilt industrial clusters, especially Taiwanese MNEs' network linkage in the mainland, should be analyzed from different perspectives (e.g., in terms of parent-subsidiary relationships or different nodes of the VC). Besides the ITE industry, further research may also be conducted using similar analysis on the machine-building and petrochemical industries, which have also been a focus of Taiwanese investment in the mainland. With this analysis, it would be possible to compare the spatiotemporal evolution of the three industries to gain new insights.

To promote the rationalization of the regional division of labor of the Taiwanese-funded ITE value module in Mainland China, the Chinese government needs to further enhance the VC in Mainland China through policy guidance. Specifically, combining the comparative advantages of different economic zones, policy regarding targeted industrial cooperation can be formulated to improve the sustainability of the ITE industry for both Mainland China and Taiwan.

1. The Bohai rim region: The innovation environment is active, the technology circle exchanges frequently, the technology market turnover and innovation factors are in the lead in the country, and the average wages of the manufacturing and software industries, as well as industrial land prices, are higher than the Yangtze River Delta. However, it has not become a hot spot for Taiwanese investment. This area could strengthen cooperation in high-value fields, such as the software design industry, the operation center of complete machine products and R\&D centers, by attracting Taiwanese investment. 
2. Yangtze River Delta area: This area is defined by an active capital market, a good atmosphere for innovation, a broad consumer market, low-tax policy, a complete set of industrial support, research and development, manufacturing, sales, and the development of ecological settlements. However, with the increase of labor wages and land prices, it is necessary to continually strengthen the localization of Taiwanese enterprises by seeking to jointly build technical standards with local governments and enterprises, jointly develop and design products in line with the mainland market, and establish special distribution channels and marketing outlets. Labor-intensive general module production and complete machine module OEM continue to transfer from this area to peripheral cities, such as Suzhou, Ningbo and even Anhui, Jiangxi and other central and western regions.

3. Pearl River Delta: This area has independent geographical advantages, as it is adjacent to Hong Kong and Macao. It has the lowest level of "foreign-funded" tax burden, and a variety of preferential policies for Taiwanese business ventures. However, it lags behind the Bohai Rim and Yangtze River Delta with respect to scientific research institutions and higher education. Therefore, it is necessary to improve the regional innovation environment, the technological research and development ability of Taiwanese enterprises, and expand the domestic market. Under the guidance of policies, Taiwanese enterprises in Shenzhen, Guangzhou and other central cities should strengthen localization in the Pearl River Delta and develop key component modules and software design and marketing modules to increase added value. Labor-intensive industries such as production of general module and whole machine OEM modules should be transferred to the lower-cost northwest Guangdong, such as Heyuan, Zhanjiang, Qingyuan, and other cities, as well as Chongqing and Sichuan.

4. West Triangle Economic Zone: This area enjoys the favorable policy toward Taiwan and the advantage that average wages in manufacturing are close to the national average. However, the scientific research level, scientific and technological personnel, and existing venture capital are insufficient. Because technology trading markets and product markets in this area are so small, the area should continue to focus on the Taiwanese-funded photoelectric and software industry.

5. Western Taiwan Straits Economic Zone: With the advantages of lower labor costs, scientific research and high-level talents, as well as the preferential policies of local government to promote transportation construction and subsidize the operating cost of manufacturers, this area can be expected to undertake the industrial transformation for the east coast and become a new Taiwanese-funded computer production base in the future. In the meantime, the area should attract Taiwanese investment from upstream and downstream enterprises to continuously improve the industrial VC and expand the market potential in the central and western regions of Mainland China.

6. Midland in Mainland China: This area has a similar labor cost advantage and scientific research potential as the West Triangle area and has the geographical advantage of being connected to both the east and west. However, it has not yet become a hotspot for Taiwanese investment. If Taiwanese businesses want to expand the market in this area, apart from striving for more preferential policy and local government cooperation, Taiwanese-funded companies need to emphasize the technology and management advantages, and set up production or research and development facilities in order to get into the market.

Author Contributions: S.W. and H.Z. conceptualized the manuscript; Y.C. and Y.G. designed the research method, conducted the analysis, prepared the original draft, and wrote the manuscript. All authors read and approved the final draft.

Funding: This research was funded by the GDAS Project of Science and Technology Development and Public Welfare (No.2019GDASYL-0103005), the National Natural Science Foundation of China (Project No. 41771136, 41771137), the key projects of technology and public welfare of priority areas in the Department of Science and Technology in the Fujian province (No.2018R1101006-2), and the GDAS Project of Science and Technology Development and Public Welfare (No. 2018GDASCX-0101). 
Acknowledgments: We would like to thank Editage [www.editage.cn] for English language editing.

Conflicts of Interest: The authors declare no conflict of interest. The sponsors had no role in the design, execution, interpretation, or writing of the study.

\section{References}

1. Ernst, D. Global production networks in East Asia's electronics industry and upgrading prospects in Malaysia. Glob. Prod. Netw. Technol. Chang. East Asia 2004, 47, 89-157. [CrossRef]

2. Sturgeon, T.J. How globalization drives institutional diversity: The Japanese electronics industry's response to value chain modularity. J. East Asian Stud. 2007, 7, 1-34. [CrossRef]

3. Sturgeon, T.J.; Kawakami, M. Global value chains in the electronics industry: Characteristics, crisis, and upgrading opportunities for firms from developing countries. Int. J. Technol. Learn. Innov. Dev. 2011, 4, 120-147. [CrossRef]

4. Li, C.Y.; Zhang, H.H.; Zhang, X. The drivers and path of high-end oriented development in electronic information manufacturing industry under modularity perspective. Appl. Mech. Mater. 2013, 9, 3188-3193. [CrossRef]

5. Ponte, S.; Sturgeon, T. Explaining governance in global value chains: A modular theory-building effort. Rev. Int. Polit. Econ. 2014, 21, 195-223. [CrossRef]

6. Croom, S.; Vidal, N.; Spetic, W.; Marshall, D.; McCarthy, L. Impact of social sustainability orientation and supply chain practices on operational performance. Int. J. Oper. Prod. Manag. 2018, 38, 2344-2366. [CrossRef]

7. Jin, Z.; Navare, J.; Lynch, R. The relationship between innovation culture and innovation outcomes: Exploring the effects of sustainability orientation and firm size. RED Manag. 2018, 1, 88-95. [CrossRef]

8. Cerchione, R.; Centobelli, P.; Shabani, A. Sustainability orientation, supply chain integration, and SMEs performance: A causal analysis. Benchmark Int. J. 2018, 25, 3679-3701. [CrossRef]

9. Cooke, P. Global production networks and global innovation networks: Stability versus growth. Eur. Plan. Stud. 2013, 21, 1081-1094. [CrossRef]

10. UNCTAD. Global Value Chains: Investment and Trade for Development. 2013. Available online: https: //unctad.org/en/PublicationsLibrary/wir2013_en.pdf (accessed on 8 June 2019).

11. Mcbeath, G.A. Foreign direct investment management and economic crisis in Asia: Taiwan's changing strategy. Manag. Int. Rev. 1999, 39, 105-135.

12. Lin, H.; Yeh, R.S. To invest or not to invest in China. Small Bus. Econ. 2004, 22, 19-31. [CrossRef]

13. Chiao, Y.C.; Yu, C.M.; Li, P.Y.; Chen, Y.C. Subsidiary size, internationalization, product diversification, and performance in an emerging market. Int. Mark. Rev. 2008, 25, 612-633. [CrossRef]

14. Hung, S.W. Development and innovation in the IT industries of India and China. Tech. Soc 2009, 31, $29-41$. [CrossRef]

15. Pananond, P. Where do we go from here? Globalizing subsidiaries moving up the value chain. J. Int. Manag. 2013, 19, 207-219. [CrossRef]

16. Dedrick, J.; Kraemer, K.L. Is production pulling knowledge work to China? A study of the notebook PC industry. Computer 2006, 39, 36-42. [CrossRef]

17. Hsu, J.Y. The dynamic firm-territory nexus of Taiwanese informatics industry investments in China. Growth Chang. 2006, 37, 230-254. [CrossRef]

18. Tsai, S.H.T.; Everatt, D. The Acer Group's R\&D Strategy: The China Decision. Silicon Dragon 2006, 197, $38-45$. [CrossRef]

19. Yang, C. Overseas Chinese investments in transition: The case of Dongguan. Eurasian Geogr. Econ. 2006, 47, 604-621. [CrossRef]

20. Chien, S.S. Institutional innovations, asymmetric decentralization, and local economic development: A case study of Kunshan, in post-Mao China. Environ. Plan. C Gov. Policy 2007, 25, 269-290. [CrossRef]

21. Chen, C.M.; Melachroinos, K.A.; Chang, K.T. FDI and local economic development: The case of taiwanese investment in kunshan. Eur. Plan. Stud. 2010, 18, 213-238. [CrossRef]

22. Lai, H.C.; Shyu, J.Z. A comparison of innovation capacity at science parks across the Taiwan Strait: The case of Zhangjiang High-Tech Park and Hsinchu Science-based Industrial Park. Technovation 2005, 25, 805-813. [CrossRef] 
23. Chen, S.H.; Wen, P.C.P. Globalization and innovation: The changing economic geography across the Taiwan Strait. Macalester Int. 2007, 18, 126-145.

24. Liu, M.C.; Chen, S.H. MNCs' offshore R\&D networks in host country's regional innovation system: The case of Taiwan-based firms in China. Res. Policy 2012, 41, 1107-1120. [CrossRef]

25. Crain, D.W.; Abraham, S. Using value-chain analysis to discover customers' strategic needs. Strategy Leadersh. 2008, 36, 29-39. [CrossRef]

26. Abraham, S.C. Strategic Planning: A Practical Guide for Competitive Success; Emerald Group Publishing: Bingley, UK, 2012.

27. Gereffi, G.; Korzeniewicz, M. Commodity chains and global capitalism. Contemp. Sociol. 1994, $24,389-404$. [CrossRef]

28. Gereffi, G.; Kaplinsky, R. Introduction: Globalisation, value chains and development. IDS Bull. 2001, 32, 1-8. [CrossRef]

29. Simon, H.A. The architecture of complexity. Proc. Am. Phil. Soc. 1962, 106, 467-482.

30. MacDuffie, J.P. Modularity-as-Property, Modularization-as-Process, and 'Modularity'-as-Frame: Lessons from Product Architecture Initiatives in the Global Automotive Industry. Glob. Strategy J. 2013, 3, 8-40. [CrossRef]

31. Fixson, S.K. The Multiple Faces of Modularity - A Literature Analysis of a Product Concept for Assembled Hardware Products; Technical Report No. 03-05; University of Michigan: Ann Arbor, MI, USA, 2003.

32. Fixson, S.K. Product architecture assessment: A tool to link product, process, and supply chain design decisions. J. Oper. Manag. 2005, 23, 345-369. [CrossRef]

33. Salvador, F. Toward a product system modularity construct: Literature review and reconceptualization. IEEE Trans. Eng. Manag. 2007, 54, 219-240. [CrossRef]

34. Schilling, M.A.; Steensma, H.K. The use of modular organizational forms: An industry-level analysis. Acad. Manag. J. 2001, 44, 1149-1168. [CrossRef]

35. Campagnolo, D.; Camuffo, A. The concept of modularity in management studies: A literature review. Int. J. Manag. Rev. 2010, 12, 259-283. [CrossRef]

36. Baldwin, C.Y.; Clark, K.B. Design Rules: The Power of Modularity; MIT Press: Cambridge, MA, USA, 2000.

37. Langlois, R.N. Modularity in technology and organization. J. Econ. Behav. Organ. 2002, 49, 19-37. [CrossRef]

38. Baldwin, C.Y.; Clark, K.B. The Option Value of Modularity in Design; Harvard NOM Research Paper, SSRN Electronic Journal, USA; 2002; Volume 3, pp. 15-18. Available online: https://papers.ssrn.com/sol3/papers. cfm?abstract_id=312404 (accessed on 8 June 2019). [CrossRef]

39. Fixson, S.K. What Exactly Is Product Modularity? The Answer Depends on Who You Ask; Working Paper, SSRN Electronic Journal, USA; MIT Sloan School of Management, 2006; pp. 37-85. Available online: https://papers.ssrn.com/sol3/papers.cfm?abstract_id=952045 (accessed on 8 June 2019). [CrossRef]

40. Fixson, S.K.; Park, J.K. The power of integrality: Linkages between product architecture, innovation, and industry structure. Res. Policy 2008, 37, 1296-1316. [CrossRef]

41. Cabigiosu, A.; Camuffo, A. Beyond the "mirroring" hypothesis: Product modularity and inter-organizational relations in the air conditioning industry. Organ. Sci. 2012, 23, 686-703. [CrossRef]

42. Sturgeon, T.; Lee, J.R. Industry co-evolution and the rise of a shared supply-base for electronics manufacturing. In Proceedings of the Nelson and Winter Conference, Aalborg, Denmark, 12-15 June 2001.

43. Gereffi, G.; Humphrey, J.; Sturgeon, T. The governance of global value chains. Rev. Int. Polit. Econ. 2005, 12, 78-104. [CrossRef]

44. Krugman, P.; Cooper, R.N.; Srinivasan, T. Growing world trade: Causes and consequences. Brook. Pap. Econ. Act. 1995, 1, 327-377. [CrossRef]

45. Balassa, B. Trade creation and trade diversion in the European Common Market. Econ. J. 1967, 77, 1-21. [CrossRef]

46. Findlay, R. Relative backwardness, direct foreign investment, and the transfer of technology: A simple dynamic model. Q. J. Econ. 1978, 92, 1-16. [CrossRef]

47. Hanson, G.H. Economic integration, intraindustry trade, and frontier regions. Eur. Econ. Rev. 1996, 40, 941-949. [CrossRef]

48. Feenstra, R.C.; Hanson, G.H. Foreign direct investment and relative wages: Evidence from Mexico's maquiladoras. J. Int. Econ. 1997, 42, 371-393. [CrossRef] 
49. Feenstra, R.C. Integration of trade and disintegration of production in the global economy. J. Econ. Perspect. 1998, 12, 31-50. [CrossRef]

50. Deardorff, A.V. Technology, trade, and increasing inequality: Does the cause matter for the cure? J. Int. Econ. Law 1998, 1, 353-376. [CrossRef]

51. Arndt, S.W. Globalization and the open economy. N. Am. J. Econ. Financ. 1997, 8, 71-79. [CrossRef]

52. Humphrey, J.; Schmitz, H. Governance and Upgrading: Linking Industrial Cluster and Global Value Chain Research; IDS Working Paper 120; Institute of Development Studies: Brighton, UK, 2000.

53. Humphrey, J.; Schmitz, H. Developing Country Firms in the World Economy: Governance and Upgrading in Global Value Chains; INEF Report; Institute for Development and Peace: Brazil, 2002; Volume 61. Available online: https://www.researchgate.net/publication/320427730_Developing_Country_Firms_in_the_World_ Economy_Governance_and_Upgrading_in_Global_Value_Chains (accessed on 8 June 2019).

54. Staritz, C.; Morris, M. Local Embeddedness, Upgrading and Skill Development: Global Value Chains and Foreign Direct Investment in Lesotho's Apparel Industry; Capturing the Gains Working Paper 20; University of Manchester: Manchester, UK, 2013.

55. Sturgeon, T.; Van Biesebroeck, J.; Gereffi, G. Value chains, networks and clusters: Reframing the global automotive industry. J. Econ. Geogr. 2008, 8, 297-321. [CrossRef]

56. Ernst, D.; Guerrieri, P. International production networks and changing trade patterns in East Asia: The case of the electronics industry. Oxf. Dev. Stud. 1998, 26, 191-212. [CrossRef]

57. Sturgeon, T.J. Exploring the Risks of Value Chain Modularity: Electronics Outsourcing during the Industry Cycle of 2001-2002; MIT IPC Working Paper; MIT Industrial Performance Center: Cambridge, MA, USA, 2003.

58. Kaplinsky, R.; Memedovic, O.; Morris, M.; Readman, J. The Global Wood Furniture Value Chain: What Prospects for Upgrading by Developing Countries; UNIDO Sectoral Studies Series Working Paper; United Nations Industrial Development Organization: South Africa, 2003. Available online: https://papers.ssrn.com/sol3/ papers.cfm?abstract_id=420080 (accessed on 8 June 2019).

59. Sturgeon, T.J. Modular production networks: A new American model of industrial organization. Ind. Corp. Chang. 2002, 11, 451-496. [CrossRef]

60. Shih, S. Me-Too Is Not My Style: Challenge Difficulties, Break through Bottlenecks, Create Values; The Acer Foundation: Taipei, Taiwan, 1996.

61. May, R.M. On the theory of niche overlap. Popul. Biol. 1974, 5, 297-332. [CrossRef]

62. Chen, J. A Study on the Space-Time Pattern and Driving Mechanism of Taiwanese Direct Investment in Mainland China; Normal University: Fujian, China, 2013. 